\title{
Comprehensive Prioritized Perspectives of CRM System for Implementation in the Developing Countries' Hospitals
}

\author{
Hossein Monem \\ Faculty of Computer Science \\ and Information System, UTM, \\ Malaysia
}

\author{
Ab Razak Che Hussin \\ Faculty of Computer Science \\ and Information System, UTM, \\ Malaysia
}

\author{
Roxana Sharifian \\ School of management \& \\ Medical Information Science, \\ Shiraz University of Medical \\ Sciences, Shiraz, Iran
}

\begin{abstract}
Research on the CRM implementation link has been fragmented due to various perspectives on CRM, especially in hospitals. Literatures show that comprehensive research on CRM implementation in healthcare is quite inadequate and lag in the hospitals in terms of IT technology implementation exist. In this study, different perspectives of the CRM implementation were reviewed. Furthermore, in order to prioritize CRM implementation perspectives, 35 high experience experts in the hospital information system, clinical information system, hospital's chief information technology officer and hospital's chief execute officer in Malaysia, Kuwait and Iran were interviewed. The empirical work in three developing countries indicates that resource, management, CRM application system, employees and patient perspectives have the highest to lowest impact. Moreover, results of the interviews showed that unlike regular customers in organizations and companies, patient's involvement as a customer, had not been a considerable impact on success and failure of CRM implementation in the hospital of the developing countries. In addition, lack of measurement models pushed CRM projects to the higher risk.
\end{abstract}

\section{Keywords}

CRM implementation, HIS, Hospital, measurement model.

\section{INTRODUCTION}

In the modern environment of business, the central critical point of all marketing activities is customer, Customer Relationship Management (CRM) has high priority for companies $[1,2]$. Organizations, companies and all enterprise need the customer to continue their business. Without customer any goal is meaningless to achieve by organizations. If the word "Customer" removes from organizations then all business will be closed immediately[3].

CRM is an outcome of marketing issue. In short description CRM gives ability to organization administrators to manage and make efficient and productive relationship with customers. CRM is an information industry term for methodologies, software, and usually internet capabilities that help an enterprise to manage customer relationships in an organized and efficient manner[4].

However all organizational activities, directly or indirectly are ended to customer related services and customer has vital role in business' activities, but There is limited research conducted in CRM area [5]. King and Burgess [6] claimed that "relationship among CRM implementation factors are not well understood" and "There is a need for stronger theoretical models of the entire CRM innovation process".

Among various types of organizations, hospitals have played critical role for their customers. In the hospital patients have played customer's role, but with different behaviors and attitudes. Patient's expectations in contrast of regular customers are quite high and different[3]. Hospitals still have lag behind many of other organizations in using information technology and it is more difficult to adopt CRM system [7]. Although we have currently seen initiatives of CRMS adoption in a number of hospitals in Iran, Malaysia and Kuwait, the percentage of successful projects is quite low in the world. A deeper understanding of the essential perspectives of CRM system implementation in the hospital can provide considerable help and useful implications to associate academics, medical CRM system manager and CRM application vendors.

To remedy the situation, we should first determine from where the problem stems. Going through the literature, it is founded that not only none of the previous researchers focused and investigated on CRM comprehensively, but also study onto hospital CRM success and failure are quite inadequate. To end these problems, holistically investigation is done onto different medical environment at Malaysia, Iran and Kuwait by authors to find out; first, what priorities exist between perspectives of previous comprehensive model, second, what differences are between regular customers of other organizations with patients in the hospitals in terms of impact on successful CRM implementation, and lastly, what measurement model could be used based on proposed exhaustive map in the hospitals.

The rest of this manuscript is structured as follows: CRM system features in hospital are reviewed and then CRM architecture and subsystem's Roles in Hospitals is presented. Background of study section is provided to previous work on CRM. And in the next part of paper, research methodology which is consist of CRM implementation perspectives and factors in the hospital is discussed. Paper is followed by results and discussion which is focused on perspectives' priorities and measurement model

\subsection{CRM System Features in Hospital}

Depending on the mission of organization; CRM should have various characteristics and features. Hung [7] discussed about critical characteristics which should be considered for healthcare CRM operations. Three characteristics are as follows:

- Little power of patients: Regular customers have lots of information about what they needed. In contrast patients have little knowledge to decide what kind of service or treatment they needed. There is a great medical information asymmetry between medical service providers and patients.

- Information Technology: The use of information technology (IT) is essential for implementing CRM. An 
effective CRM requires a synergistic integration of the strategy, people and technology of an organization [8].

- Customer Loyalty and Lifelong Value: The CRM in the healthcare industry seeks to obtain patients' loyalty and provide lifelong value. The more loyal the customers are in each transaction, the less investment is needed by the organization. [9].

\subsection{CRM Architecture and Subsystem \\ Roles in Hospitals}

In order to create strength and sustain a relationship between hospitals and patients, Hospital Information System (HIS) applications should be equipped by a CRM system. In order to release the potential of CRM usage to the greatest extent, CRM should be seamlessly integrated with HIS. Practically, majority of data which is needed for CRM are preparing by HIS. If all the data collected can be analyzed appropriately through data warehousing and multi-dimensional analysis technologies, medical institutions can provide closer relationships, personalized medical services, and two-way communication $[7,10]$.

CRM architecture is depicted in figure 1. Tomé and Vardasca [11] used of Patient Relationship Management (PRM) in their PRM application architecture to mentioned CRM, because patients have played roles of customer in the hospitals.

PRM application system is formed by various units. Following descriptions presented the most important portions of PRM:

- Database: All the PRM system is supported by a database that stores the relevant information and

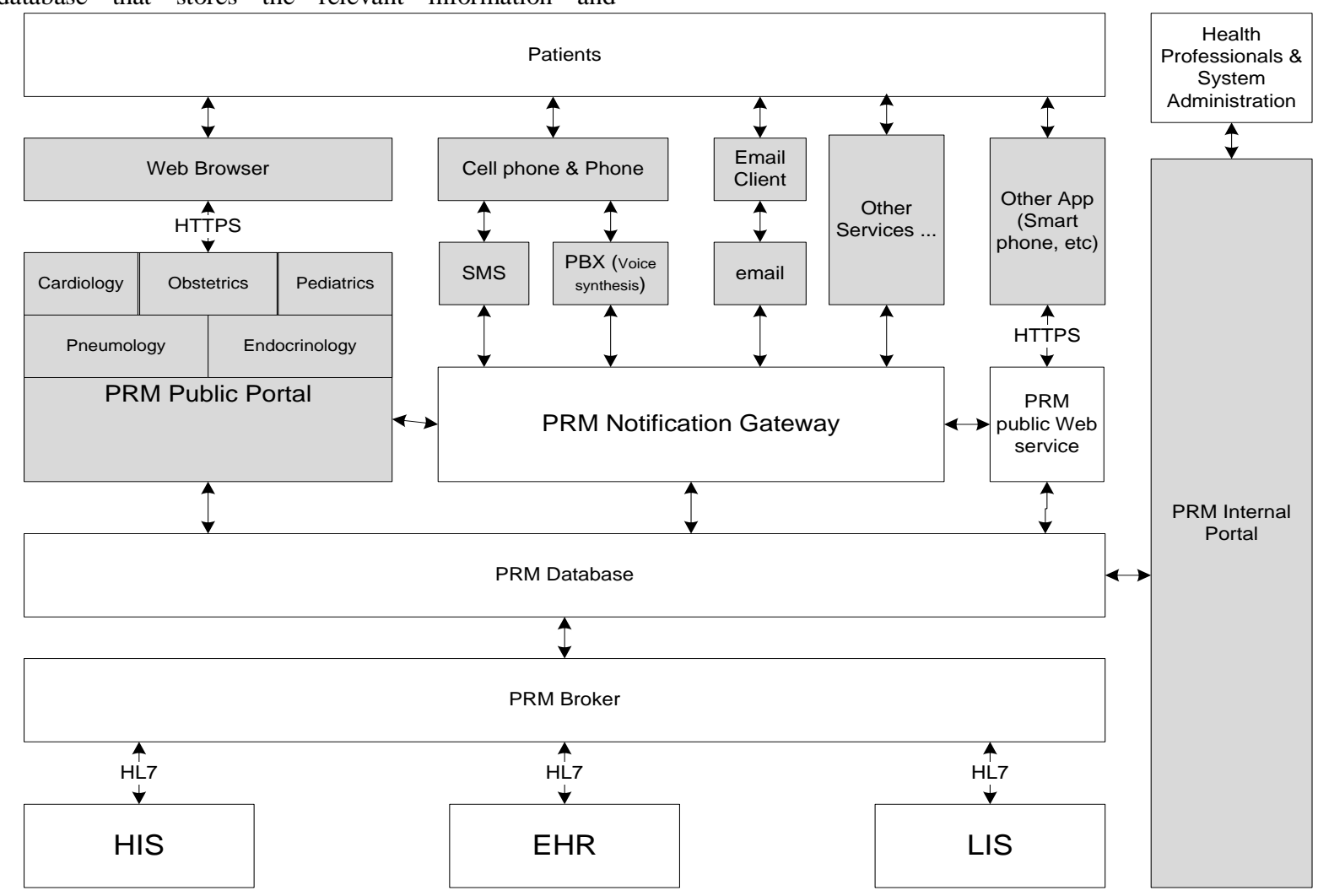

Figure 1. Patient relationship management system architecture [11]

Surprisingly, PRM system is not popular concept in hospitals which were investigated in the north of Malaysia[12]. Young expressed that CRM is not a popular concept among chief executives officers (CEOs) of hospitals [13]. Nevertheless, PRM systems play very important roles in hospitals. In configuration for the normal functioning of the system[11]. These data are provided by various units of HIS such as Laboratory Information Management System (LIMS), Clinical Information System (CIS), Radiology Information System (RIS), etc.

- Broker: The Broker function is to handle all the communication with information systems that there is a necessity of integration. All communication should be secure and broker does it. This broker shall have the ability to communicate with Health Level 7 (HL7) [11] and the other medical information system in the other location.

- Internal portal: "There will be a transversal portal, only accessible inside the hospital to administrators to configure the system, and to health care professionals to send educational information to the population, and to manage the applications deployed on the portal. It will work as the back-office of the system. The authentication on the internal portal is achieved using the internal Active Directory so the users do not need to remember another password, and the system administration should not be available outside of the organization"[11].

- Public portal: The main front-end and the first entry point is the PRM Public Portal. This is where patients and population register into the system. In this portal there should be provided all medical services which are deliverable via net. 
Moreover, PRM systems are considered to be an effective tool for the prediction of the future needs of the patients.

PRM subsystems appear in different modules under HIS applications. Patient registration, accounting and finance, patient billing, laboratory, radiology, human resource pay rolls, stores, pharmacy and patient discharges.

All the above subsystems are related with patient from financial perspective and decision support system (DSS) and clinical information system are from treatment perspective[12].

CRM system has various roles in the hospitals which are listed as follow:

- Optimizing revenues and improving patient health, relationships, and loyalty.

- Could deliver greater Return on Investments (ROI) and it seems to be the perfect solution for the major problems at the healthcare industry.

- An essential cost-effective approach to maintain long-term customer relationships.

- Increasing the transparency of cost and resource allocation within the hospital.

- The mapping of the documentation during the patients' treatment is one of the major cost reduction areas that the CRM systems have handled effectively in the hospitals.

- Reducing the costs associated with the no-shows or cancelled appointments.

Figure 1, depicted the PRM system architecture. PRM architecture clears that patients communicate with special media. Generally, in developed countries, Hospitals are using of web browsers, cell phone and phone, email, other electronic services and applications to serve medical services to patients. The mentioned medias have played critical role to patient involvement during PRM implementation and adoption. Lack of each one of them decreases involvement of patients. Medical services such as cardiology, obstetrics, pediatrics, pneumology and endocrinology are delivered by hospitals and medical centers via PRM public portals.

\subsection{CRM Implementation's Failure Rate}

Before implementing CRM, organization has to evaluate the fit of CRM in their organization, current CRM capabilities and good reason to implementing CRM, together with the good implementing strategy [14]. However, CRM is a concept that requires suitable business process, effective system integration, evaluation process after implement Customer Relationship Management System (CRM Evaluation Process) [15] and CRM feedback which able to increases organization CRM's efficiency [16] where the business processes which adapt to support CRM practice can enable the companies to increase the relationship between employee, customer and supplier by creating a good environment for operate business [17].

Moreover, focusing on the organization's cultural and practical requirements, the organization can more easily overcome employee's resistance to adopting new applications, without above factor, no CRM project can successfully implement, although the best CRM has been installed [18]. The study of Yi-Te [19] also support that change management is very important to the success of CRM implement. While technology factor is only some part of the project, people are the key to making with CRM success, while top management support should focus not only CRM system but also arrangement of the personal in order to increase level of the cross functional integration of process, people, operations and technology [19].
Positive relationship between CRM and organization performance have been approved by some academic researchers [20-22]. Billions of dollars are spent each year by business firms on CRM application [23, 24], but many disappointed results were shown by many business reports, academic experts and research groups [24-27].

In reality, there have been many failed CRM projects. In a research it has been mentioned that about $70 \%$ of CRM projects result in either loss or no bottom line improvement in company performance [28]. Table 1 presents a summary of CRM failure during 2001 to 2009.

Table 1. Summary of CRM failure during 2001 and 2009 [28]

\begin{tabular}{c|c|c}
\hline Researcher & Year & Percentage \\
\hline Gartner Group & 2001 & $50 \%$ \\
\hline Butler Group & 2002 & $70 \%$ \\
\hline Selling Power, CSO Forum & 2002 & $69.3 \%$ \\
\hline AMR Research & 2005 & $18 \%$ \\
\hline AMR Research & 2006 & $31 \%$ \\
\hline AMR Research & 2007 & $29 \%$ \\
\hline Economist Intelligence Unit & 2007 & $56 \%$ \\
\hline Forrester Research & 2009 & 47 \\
\hline
\end{tabular}

As it mentioned in table 1, Gartner Group reported 50\% failure rate in 2001. For year 2002, Butler Group and Selling Power, CSO Forum mentioned to $70 \%$ and $69.3 \%$, respectively. Failure rate during 2005 to 2007 sharply decreased which are reported by AMR Research, although in 2007 the other research group mentioned to the $56 \%$ failure rate which is in contrast with AMR Research result. Forrester Research for year 2009 reported $47 \%$ failure rate for CRM implementation in the world. However, for 2003, 2004 and 2008 are not any report in the table1, but risk in the CRM system implementation is quite high.

\section{RESEARCH METHODOLOGY}

The usefulness of every theory depends on proper replications, extensions, and generalizations that provide new insights and add to the existing stock of knowledge [29]. In order to achieve to the researches' questions, we reviewed several studies linking CRM and information system success model and elaborated on their important points. Among various information system success models, Deloan and McLean IS success model selected as a basic theory and UTAUT applied for distinguishing factors for each perspective. Confirmatory factor analysis has been done to confirm them and then, initial proposed model has been shaped.

Due to data availability and similarities in cultures, between developing countries, three countries consist of Malaysia, Kuwait and Iran were chosen. High experienced hospital information system (HIS) adopter, clinical information system (CIS) expert, chief execute officer (CEO), chief IT officer (CITO) and wards' in charges were selected, interviewed and discussed.

In order to prioritize concluded perspectives, two sets of five-point likert scale questions were designed. Each set was comprises of five questions. For perspective solidification, respondents were asked to show their level of agreement on resources, management, employee, CRM application system and patient by checking each one of prepared answers. Fivepoint for each questions were "strongly disagree", "disagree", "fair", "agree" and finally "strongly agree". Results of this part of the study approved and solidified five concluded perspectives which influence CRM implementation in the hospital. 
In order to determine the level of impact of each of perspectives, in the second set of questions, respondents were asked to mention the impact of each perspective by indicate to prepared point. In this set, five-point likert scale was used as well as first set. To better understanding, second set presented in table2. One mentioned to the least impact and five mentioned to the greatest impact on the CRM implementation onto the hospital.

Table2. Questions for determining level of impact

\begin{tabular}{c|c|c|c|c|c|c}
\hline \multirow{2}{*}{ QNo } & \multirow{2}{*}{ Perspectives } & \multicolumn{5}{|c}{ Level of impact } \\
\hline & & $\mathbf{1}$ & $\mathbf{2}$ & $\mathbf{3}$ & $\mathbf{4}$ & $\mathbf{5}$ \\
\hline 1 & Employee & & & & & \\
\hline 2 & Management & & & & & \\
\hline 3 & Resources & & & & & \\
\hline 4 & Patient & & & & & \\
\hline 5 & App System & & & & & \\
\hline
\end{tabular}

This research examined what critical perspectives and factors affect implementation of CRM system in the hospital. It summarized the perspectives which influence the implementation information technology into three scopes: features of organization, features of application and characteristics of customers (see figure2). Although each cluster of the following groups in figure 2 has an impact on the CRM system implementation individually, but they also influence to each other and has correlation.

Features of organization generally focused in resources, management and employee which are common each organization. These features are considered as intraorganizational features. Features of CRM system application, mention to the application competency which influences users of the software. And characteristics of customer focus to the patients requirements for involvement, perception and patients' trust.

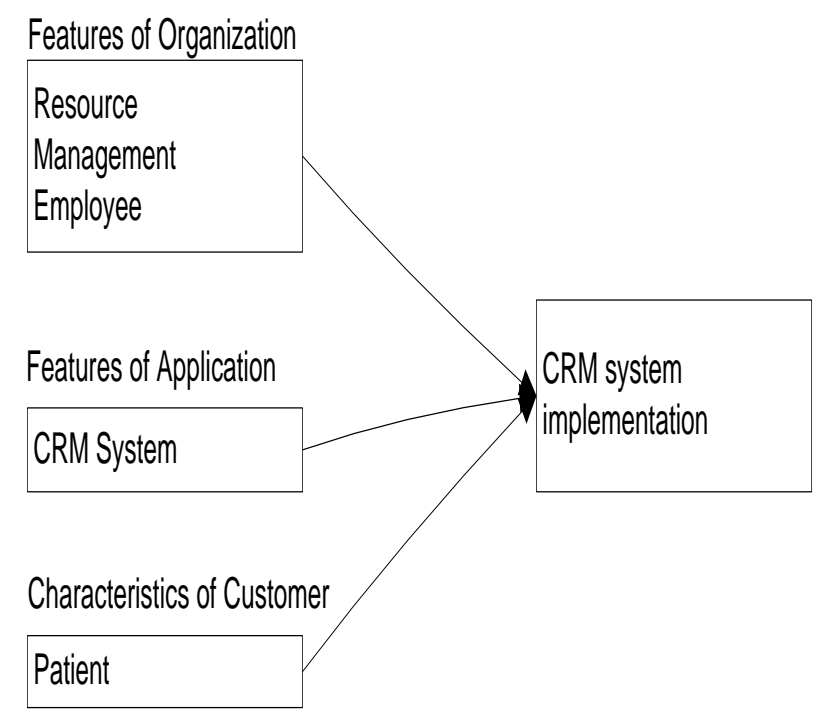

Figure2. Research model

\subsection{CRM Implementation Perspectives and Factors}

H. Monem et al, [3, 30] listed perspectives and factors of CRM implementation in hospital (see figure3), but he didn't discuss about priorities which exist among perspectives. Normally each one of the perspectives has not same impact on CRM before and during implementation process in hospital. Five various perspectives which affect each CRM system are namely resource, management, CRM application system employee, and patient. Each one of them has individual factors that are listed in table3. Application factors which affect CRM application competency is consist of; data quality, relative advantages, application customization, application complexity, integrity among all parts of application and preparing integrity to the other installed applications, flexibility during maintenance periods, usability in usage, user privacy and to be usefulness for all stakeholders in the hospital. All these factors influence managers, employee and patients to be involved or not, accept or reject the CRM application.

Table3 also shows resource factors which consist of infrastructure and technological views[31]. Complete definition of CRM technologies which is based on META group segmentation, divides CRM technology into collaborative, operational, and analytical categories. Keramati [31] pointed out that "Different characteristics of infrastructural CRM resources show that they can be divided into "human CRM resources" and "organizational CRM resources" ". In other research, technological view of resource factors mentioned to what technical resources such as type of hardware and software infrastructures are need. These factors are depending directly on medical organization's size [7], application's architecture and numbers of end users.

Table3.CRM implementation perspectives and factors $[3,30]$

\begin{tabular}{|c|c|}
\hline Application Factors & Resource Factors \\
\hline Data Quality & Infrastructure \\
\hline Relative advantages & Technological \\
\hline Customization & Management Factors \\
\hline Complexity & CEO \& CITO \\
\hline Integration & Awareness \\
\hline Flexibility & Readiness \\
\hline Usability & Support \\
\hline Privacy & Involvement \\
\hline Usefulness & Measurement \\
\hline Patient Factors & Employee Factors \\
\hline Customer Involvement & IT Capability \\
\hline Trust & Motivating \\
\hline Perception & KM Capability \\
\hline & Training \\
\hline
\end{tabular}

On the one hand, in the following map (figure3), which perspective has more impact on CRM implementation in the hospital is not clarified and on the other hand, prioritization among perspectives is highly needed for hospitals' chief executive officer and hospitals' chief information technology officer to manage implementation effectively. The more information about contributed perspectives and factors makes the most successful rate in CRM implementation. 


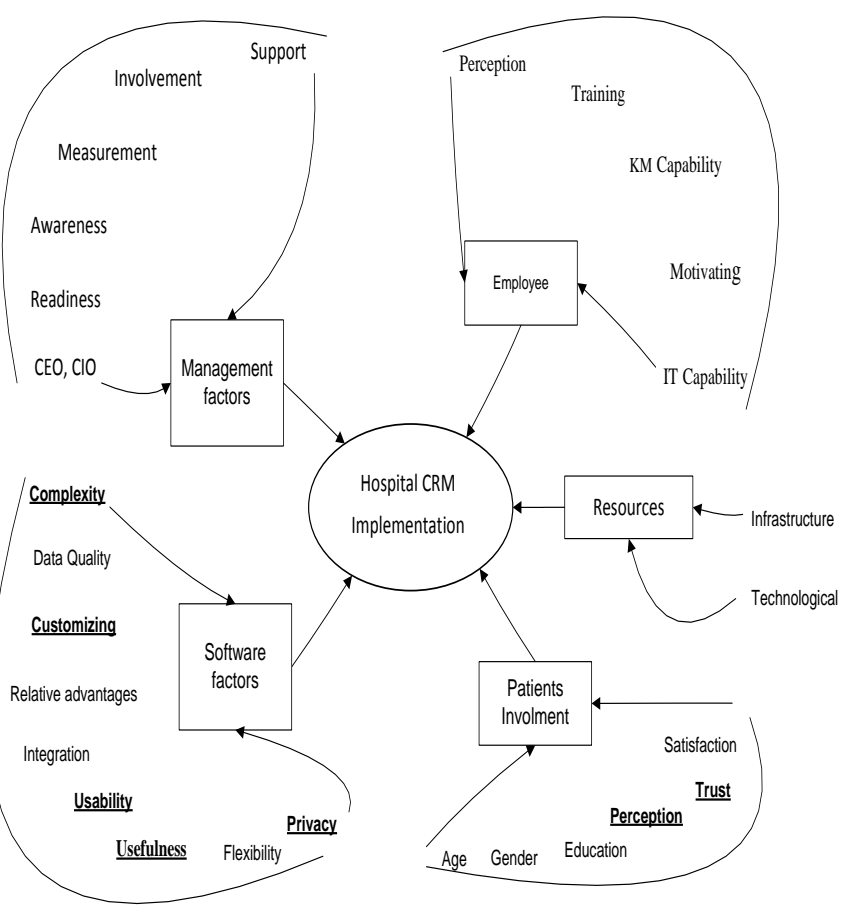

Figure3. Exhaustive map for CRM implementation[3]

Management factors should satisfy implementation and adoption process by focusing on chief executive officer, chief IT officer, awareness, readiness, support, involvement and measurement. CEO and CITO have crucial role during IT project implementation and adoption process in the hospital. IT capability and involvement of the CEO and CITO are considered here which influenced implementation surprisingly. Moreover, progress measurements and monitoring all activities which are related, should be done and supported by executive managers. While awareness mentions to gain board knowledge of strategic potential of IT [6], readiness talks about mental, physical readiness and technological availability [32]. Another dimension which is listed in table 3 is employee factors. Employee factors comprise of IT capability, motivating, KM capability, training and perception of staff which are users of CRM systems.

Hung claimed that if employees in small organizations have more knowledge of information systems, then they will be more likely to adopt the information systems [7]. As Ettlie [33] explained, staff must have some knowledge of IT innovation in order to use more innovative IT. Motivation mentioned what value added is defined for CRM system users. The meaning of knowledge management capabilities is that organizations based on reliable information capture, manage, and transmit real-time customer product and service information in order to enable organizations to make rapid decisions and improve customer response [34, 35]. The preparation for Information System (IS) training by CRMS vendors for hospital staff can alleviate technological barriers in the implementation stage. This study suggests that if CRM application contractor could provide consultation or pretraining services to assist hospitals prepare related IS capabilities, then that would improve the willingness for CRM application implementation. And finally, the awareness of IS from the potential implementing organizations is importantly used for judging whether IS will be implemented [7].

Customer involvement, trust and perception of the customer in the hospital are considered as patient's factors which are mentioned in table3. However customers' trust and perception are investigated in the other field studies but no study was founded in healthcare to discuss trust as a factor which influences CRM system implementation in the hospital. Patients' trust; mention to the situation that patient believes and accept the hospital's CRM application. Perception of the patients is a basic step in order to achieve to the patients' trust. More perception of the patient lead to more patient's trust.

\section{RESULTS AND DISCISSION 3.1 Perspectives' Priority}

On the one side, perspective's priority cannot be measured directly by quantitative instruments and, on the other side, specifying indicators for priority measurement is different from one hospital to others. To end these problems, 35 experts who had more than 10 years experience in HIS and CIS implementation beside of CIO and CITO and wards' in charges were chosen and interviewed in three developing countries. Table 4 shows the final result of the interviews in the Malaysia, Kuwait and Iran. However, considering all perspectives during the implementation process is crucial for successful implementation, but as it mentioned in the table4, among all of perspectives, some of them have more influence during CRM implementation period. The results show that resources have the highest priority, and patient perspective has the lowest.

Table4. Priority of the perspectives

\begin{tabular}{c|c|c|c}
\hline Priority & Perspective & $\begin{array}{c}\text { Persons } \\
\text { out of 35 }\end{array}$ & Percentage \\
\hline 1 & Resource & 24 & $69 \%$ \\
\hline 2 & Management & 25 & $71 \%$ \\
\hline 3 & CRM System & 21 & $60 \%$ \\
\hline 4 & Employee & 19 & $54 \%$ \\
\hline 5 & Patient & 22 & $62 \%$ \\
\hline
\end{tabular}

As it is listed in table4, 24 respondents out of 35 respondents claimed that hospital's resource has the highest priority among other perspectives that is equal to 69 percent.

The rest of respondents mentioned to the management as the second highest important perspective during CRM implementation in the hospital with 23 percentages. Patient with $0 \%$, employee with $3 \%$ and CRM application system with $5 \%$ are the other expressed for the highest priority. Respondents believed that hospital's resources play the backbone role for CRM project implementation, and without resources IT projects will not be a successful project. Majority of the respondents had been same recognized about perspectives' priority.

The second crucial perspective which is confirmed by majority of experts is management. Respondents pointed out that after resources; management has the highest impact on before and during the CRM implementation process. $71 \%$ of them confirm this issue. The rest of the respondents mentioned to the resources with $18 \%$, CRM application system with $6 \%$ and employee with $5 \%$. None of the respondents mentioned to the patients as an effective factors in this level of impact.

CRM system application has third rank in the priorities. This issue is confirmed by 60 percentages of respondents. 21 respondents out of 35 approved this priority for CRM system application. Employee was the second choice for third rank by $31 \%$ of respondents. Patient's perspective with $6 \%$ and management with $3 \%$ were the rest of two candidates for third rank. Resource didn't get any points. 


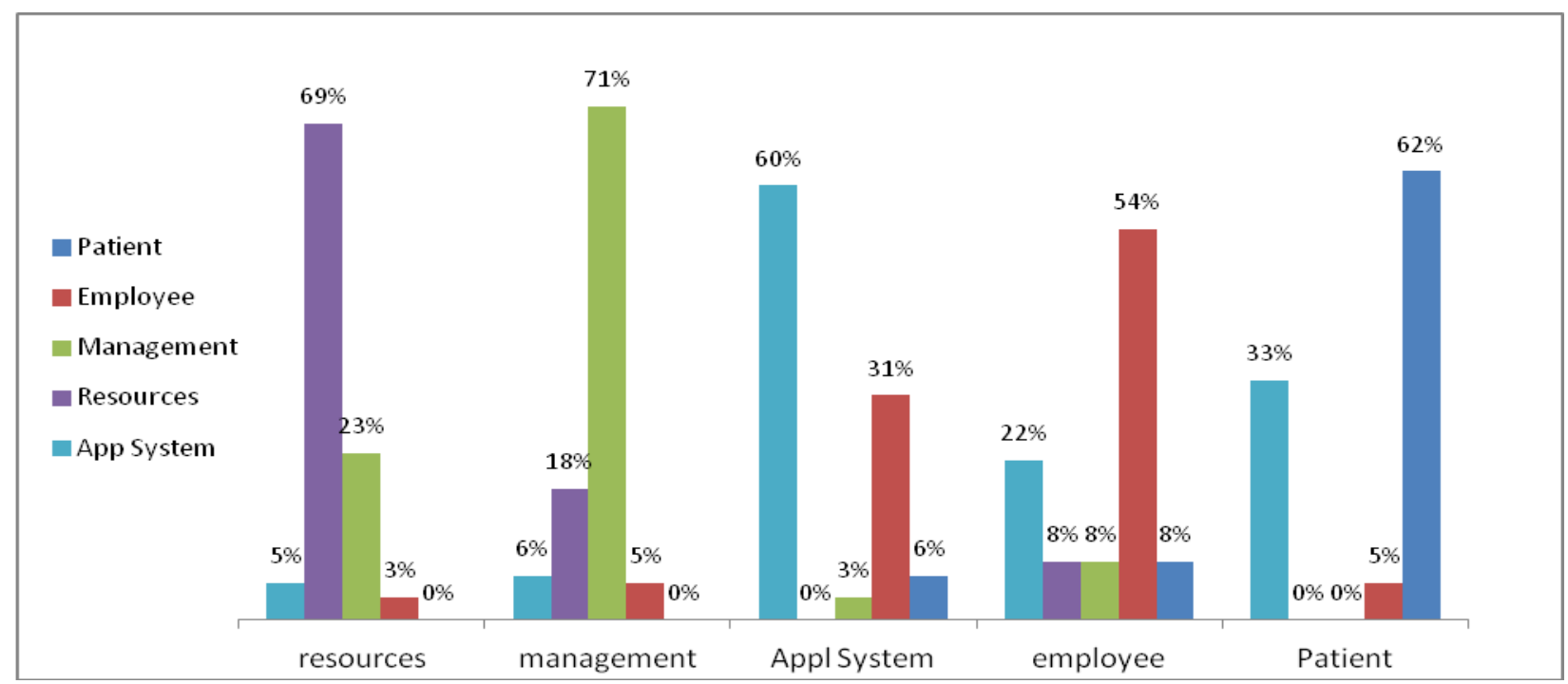

Figure 4. The perspectives' priorities

Fourth rank is occupied by employee perspective. As it listed in table 4, 19 respondents out of 35 respondents expressed this issue. 54\% of respondent approved fourth priority for employee's factors. CRM application system, management, resources and patients could take $22 \%, 8 \%, 8 \%$ and $8 \%$, respectively.

Ultimately, patient perspective received last position of priorities. $62 \%$ of respondent mentioned to the patient perspective. This percentage is equal with 22 persons out of 35 respondents. The other experts mentioned to the CRM application system and employee as second and third candidate for this position.

According to interviews, patients have not been a considerable impact on the CRM implementation in the current level of CRM implementation in the developing countries' hospitals. Because of the CRM system should be used by patient and CRM system must be acceptable for them. If CRM application is useful, perceptible, trustable and friendly in use for patient, then application satisfies patient expectations. However, the role of patients is critical for IT project, but during our investigation, we founded out that in selected developing countries, all patients must follow HIS regulations, which used to serve medical services in the hospitals. Practically, in the developing countries, CRM system in the hospital is not mature and is not a popular concept. At the selected countries, most of the hospitals and laboratories didn't deliver medical services via the net.

CRM concept is hidden under HIS applications. Therefore, is limited in the hospitals. Delivering services such as collecting diagnostic's results via the internet is under developing and the rest of the medical services arranged when the patient comes to the medical center.

\subsection{Measurement Model}

In order to increase CRM implementation success rate, each one of IT projects should be considered via different points of views. Organizational point of view is discussed in the previous paragraphs. This view is a need for resource assignment, training plan and, etc. project managers such as CRM system vendors and CEO and CITO should control whole tasks and activities during CRM implementation. For this purpose, instead of organizational point of view, IT project managers need more measurement models.
Measurement models help project administrators to deal with project as good as possible.

In this part of paper, measurement model of the exhaustive map is presented in figure5. In order to produce this model, five constructors were considered. Based on DeLoan and McLean IS success model, not only we need to measure each one of the constructors, but also we have to measure the effect of them on the intention of use, user satisfaction and NET benefit. Beside of the proposed map, measurement model for factors measurement is highly recommended. Due to role of measurement, control and monitor the implementation factors, measurement model categorize factors in different constructors.

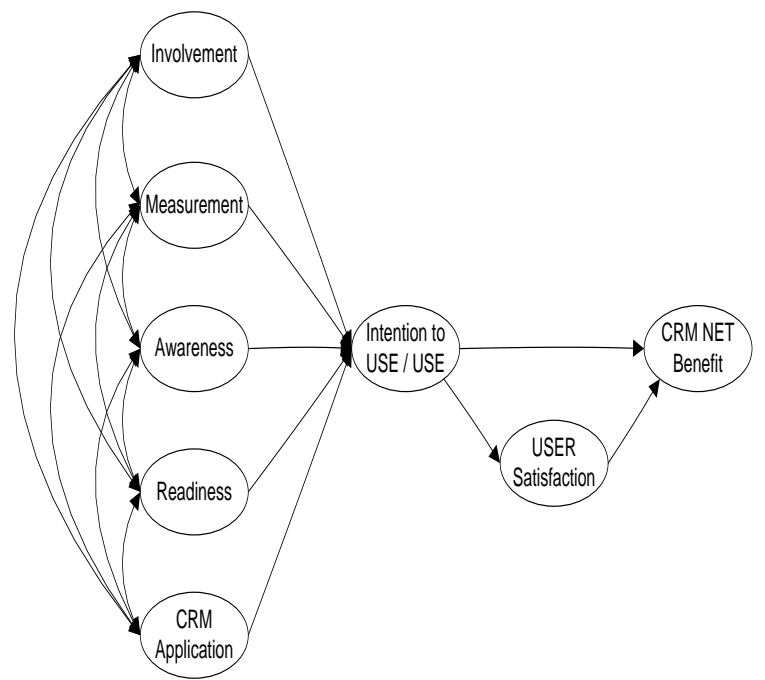

Figure5. Measurement model for CRM implementation

As it was shown in figure5, measurement model consists of involvement, application competency, measurement, readiness and awareness. All of those constructors are latent. Hidden constructors could not measure directly and should be measured by indicators. Factors which were mentioned in table3 are indicators that should be assigned to the constructors in the different category. Not only constructors should be measured by their indicators, but also correlation between each of constructors should be measured. 


\section{CONCLUSION}

Inadequate holistic study on CRM implementation in hospitals and the lag in terms of IT project implementation promoted authors to conduct this study. Three developing countries in the Asia had been chosen by authors. Next, in order to confirm and prioritize the contributed perspectives, 35 high experienced HIS and CIS adaptors beside of high experienced CEO, CITO and wards' in charges in Malaysia, Kuwait and Iran were selected and interviewed. The results of interviews show that resources, management, CRM system application, employee and patients have the highest to the lowest priority in three selected developing countries. 69 percent of respondents mentioned to resources as the highest priority. 71 percent to management, 60 percent to CRM system application, 54 percent to employee and 62 percent of respondent mentioned to the patient perspective. Majority of respondents pointed out that due to immature CRM system application, patient cannot be involve to CRM implementation and adoption process and therefore, patients have not been a significant impact on success or failure of CRM in the hospitals. According to the results of interviews, lack of a measurement models for implementing CRM system project in the hospitals push CRM project to the failure.

\section{ACKNOWLEDGMENTS}

I would like to thank all people who help us to conduct this investigation in Iran, Kuwait and Malaysia. Especially, I would like to give my deepest gratitude to UTM, which supported us by international doctoral fellowship (IDF).

\section{REFERENCES}

[1] R. T. Rust, et al., "Driving customer equity," New York, NY2000.

[2] B. Karakostas, et al., "The state of CRM adoption by the financial services in the UK: An empirical investigation.," Information \& Management, vol. 42, p. 853-863, 2005.

[3] Hossein Monem, et al., "CRM Software Implementation Factors in Hospital (Software \& Patient Perspectives )," in 5th Malaysian Software Engineering Conference (MySEC), Malaysia, 2011.

[4] InfoLific. (2010, CRM definition. Available: http://infolific.com/technology/definitions/computerdictionary/crm/

[5] Sarmad Alshawi, et al., "Organizational, technial and data quality factors in CRM adoption - SME perspective," ELSEVIER, 2011.

[6] Stephen F. King and T. F. Burgess, "Understanding success and failure in customer relationship management," Industrial Marketing Management vol. 37, pp. 421-431, 2008.

[7] Shin-Yuan Hung, et al., "Critical factors of hospital adoption on CRM system: Organizational and information system perspectives," Decision Suport System, 2010.

[8] B.K. Reddy and G. V. R. K. Acharyulu, "Customer relationship management (CRM) in health care sector-a case study on master health check," Journal of the Academy of Hospital Administration, vol. 14, 2002.
[9] T.O. Jones and W. E. S. Jr., " Why satisfied customers defect," Harvard Business Review, vol. 73, pp. 88-91, 1995.

[10] N. Ramakrishnan, et al., "Mining Electronic Health Records," Computer, vol. 43, pp. 77-81, 2010.

[11] H. M. M. Tomé R. Vardasca, "Patient Relationship Management in public healthcare settings System architecture," in IEEE ICC 2011 proceedings, Lisbon, Portugal, 2011.

[12] Khalid Rababah, et al., "A Study of the Perception of the Benefits of Customer Relationship Management (CRM) System in Malaysian Private Hospitals," presented at the 2010 International Conference on Business and Economics Research, Kuala Lumpur, Malaysia, 2011.

[13] T. Young, "hospital CRM: unexplored frontier of ravenue growth?," Healthcare Financial Management (HFM), vol. 61, pp. 86-90, 2007.

[14] T. Nguyen, Sherif, J. \& Newby, M. , "Strategies for successful CRM implementation," Information Management \& Computer Security, vol. 15, pp. 102-115, 2007.

[15] M. Zineldin, "The royalty of loyalty; CRM, quality and retention," Journal of Consumer Marketing, vol. 23, pp. 430-437, 2006

[16] T. Palsinghtoor, "Creating competitive edge through improved customer relationship management," Business Strategy Series, vol. 10, pp. 55-60, 2009.

[17] R. Skrinja, Vuksic,V.B. \& Stemberger, M.I. , "The impact of business process orientation on financial and non-financial performance. ," Business Process Management Journal, vol. 14, pp. 738-754, 2008.

[18] A. P. Lorenzon, L "The Role of Social and Cultural Contexts for the Implementation of CRM Projects," ICFAI Journal of Knowledge Management, vol. 6, pp. 79-96, 2008.

[19] W. Yi-Te, "Applying the Strategic Approach to Assess Customer Relationship Management," International Journal of Organizational Innovation, vol. 2, pp. 186 $205,2010$.

[20] Sin, et al., "CRM: Conceptualization and scale development," European Journal of Marketing, vol. 39, p. 1264-1290, 2005.

[21] T. R. Coltman, "Where are the benefits in CRM technology investment?," in Proceedings of the 39th Hawaii International Conference on System Sciences, Hawaii,USA., 2006.

[22] S. Mithas, Krishnan, M. S., \& Fornell, C. , "Why do customer relationship management applications affect customer satisfaction?," Journal of Marketing, vol. 69, p. 201-209, 2005

[23] E. W. T. Ngai, "Customer relationship management research (1992-2002) an academic literature review and classification," Marketing Intelligence \& Planning, vol. 23, p. 582-605, 2005.

[24] A. R. Zablah, et al., "An evaluation of divergent perspectives on customer relationship management: Towards a common understanding of an emerging 
phenomenon.," Industrial Marketing Management, vol. 33, p. 475-489, 2004.

[25] K. A. Richards, \& Jones, E., "Customer relationship management: Finding value drivers," Industrial Marketing Management, vol. 37, p. 120-130., 2008.

[26] J. H. F. Chen, \& Wang, E. T. G. , "Internalization in technology innovation: A case of CRM adoption.," in Proceedings of the 39th Hawaii International Conference on System Sciences, Hawaii, USA., 2006.

[27] B. Heinrich, "Transforming strategic goals of CRM into process goals and activities," Business Process Management Journal, vol. 11, p. 709-723, 2005.

[28] M. Krigsman. (2009, CRM failure rates: 2001-2009. Available: http://www.zdnet.com/blog/projectfailures/crm-failurerates-2001-2009/4967

[29] R. Santhanam and E. Hartono, " Issues in linking information technology capability to firm performance," MIS Quarterly, vol. 27, p. 125-153, 2003.

[30] Hossein Monem, et al., "Organizational Perspective of CRM Implementation Factors in Hospital " in Second International Conference on Information System (ICRIIS 2011), Malaysia, Kuala Lumur, 2011.
[31] Abbas Keramati, et al., "Aprocess-oriented perspective on customer relationship management and organizational performance: An empirical investigation," ELSEVIER: Industrial Marketing Management, 2010.

[32] Hugh Wilson, et al., "Factors for Success in Customer Relationship Management (CRM) Systems," Journal of Marketing Management Science, vol. 18, pp. 193-219, 2002.

[33] J. E. Ettlie, "What makes a manufacturing firm innovative?," Academy of Management Executive, vol. 4, pp. 7-20, 1990.

[34] M. Alavi and D. Leidner, " Knowledge management systems: emerging views and practices from the field," in Proceedings of the 32th Hawaii International Conference on System Sciences, 1999, pp. 1-11.

[35] D. Jutla, et al., "Enabling and measuring customer relationship management readiness, on System Sciences," in Proceedings of the 34th Hawaii International Conference, Maui, Hawaii, 2001, pp. 1-10. 